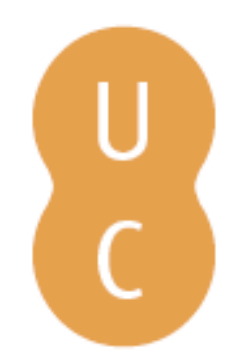

\title{
pommalina
}

\section{Acerca de los imaginarios trágicos de alteridad y su pervivencia en el teatro argentino actual: Antígona(s) y Medea(s)}
Autor(es):
Gambon, Lidia
Publicado por: Centro de Estudos Clássicos e Humanísticos da Universidade de Coimbra; Imprensa da Universidade de Coimbra
URL persistente:
URI:http://hdl.handle.net/10316.2/30242
DOI:
DOI:http://dx.doi.org/10.14195/978-989-721-038-9_24
Accessed : $\quad$ 26-Apr-2023 15:29:45

A navegação consulta e descarregamento dos títulos inseridos nas Bibliotecas Digitais UC Digitalis, UC Pombalina e UC Impactum, pressupõem a aceitação plena e sem reservas dos Termos e Condições de Uso destas Bibliotecas Digitais, disponíveis em https://digitalis.uc.pt/pt-pt/termos.

Conforme exposto nos referidos Termos e Condições de Uso, o descarregamento de títulos de acesso restrito requer uma licença válida de autorização devendo o utilizador aceder ao(s) documento(s) a partir de um endereço de IP da instituição detentora da supramencionada licença.

Ao utilizador é apenas permitido o descarregamento para uso pessoal, pelo que o emprego do(s) título(s) descarregado(s) para outro fim, designadamente comercial, carece de autorização do respetivo autor ou editor da obra.

Na medida em que todas as obras da UC Digitalis se encontram protegidas pelo Código do Direito de Autor e Direitos Conexos e demais legislação aplicável, toda a cópia, parcial ou total, deste documento, nos casos em que é legalmente admitida, deverá conter ou fazer-se acompanhar por este aviso.

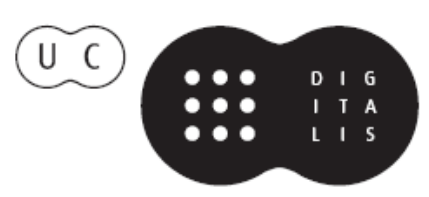




\section{De ayer a hoy}

\section{Influencias clásicas en la literatura}

\section{Aurora López, Andrés Pociña, Maria de Fátima Silva (coords.)}




\section{ACERCA De los imaginarios TRÁGicos DE ALTERIDAd Y SU PERVIVENCIA EN EL TEATRO ARGENTINO ACTUAL: Antígona(s) y MedeA(s)}

Lidia Gambon

Universidad Nacional del Sur

Difícil comenzar un trabajo referido a la alteridad y su presencia en el imaginario dramático de la antigüedad griega sin hacer referencia al conocido pasaje de Diógenes Laercio (Vit. Phil. 1.33.10-34.4) ${ }^{1}$ que atribuye a los filósofos -Sócrates o Tales- aquella antitética división tripartita sobre la que habría de cimentarse la identidad del hombre heleno. Hombre/bestia, varón/mujer, griego/bárbaro definen, entre otros, un sistema organizado de diferencias, conforman los lugares de oposiciones sustanciales a través de las que, para el orden cultural griego, se configura su imaginario, según podían señalarlo sus propios pensadores y según se mostró y demostró, asimismo, en la construcción y representación de esta alteridad en el drama ático ${ }^{2}$.

En efecto, la noción de 'imaginario', que permite -como ha sido señalado ${ }^{3}$ poner el acento en la complejidad y diversidad de las sociedades, aplicada a la antigüedad griega deja ver fundamentalmente el lugar significativo que ocupa su teatro. Así lo advertía P. Vidal-Naquet (1997), exponente conspicuo de la escuela antropológica francesa, al definir en esencia a la tragedia antigua como una reflexión sobre el "Otro". Y es que la tragedia griega fue en buena medida el género que "inventó" a los "Otros", la creación simbólica que dio vida a esa alteridad marginal y temida, tan susceptible a la desviación de la norma, considerada digna de censura, control o rechazo, aunque imposible de ignorar, en la medida en que le permitía a la polis reflexionar e interrogarse a sí misma. Género "unddeniably androcentric” (Foley, 2001: 12), la tragedia dio sobre todo cuerpo y voz en sus personajes a lo "Otro" femenino. Y a la par que afirmó en la representación del mito la concomitancia de los imaginarios de alteridad, expuso, a través del carácter multifacético de sus personajes, la complejidad de sus variadas facetas. Acaso ningún ejemplo resulte en este

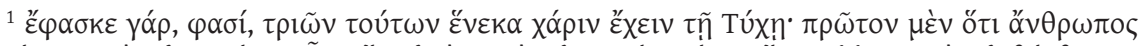

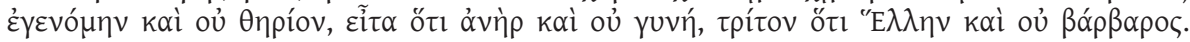
[«Decía, dicen, que daba gracias a la fortuna por estas tres razones: primero porque nací hombre y no bestia, luego porque soy varón y no mujer, en tercer lugar porque soy heleno y no bárbaro'»].

${ }^{2}$ P. Cartledge añade otros dos pares más, además de los que se señalan aquí, estableciendo así cinco dicotomías en las que se funda la identidad del hombre heleno (griego/bárbaro, hombre/ mujer, ciudadano/extranjero, hombre libre/esclavo, dioses/mortales). Cfr. Cartledge (1993).

${ }^{3}$ Cfr. Le Goff, citado por Escobar Villegas (2000: 114-115).
} 
sentido más emblemático que el de la misma Medea, esposa extranjera, mujer bárbara y hechicera poderosa, a la que Eurípides invistió de rasgos paradójicos al hacerla portavoz de la problemática matrimonial y la experiencia femenina de la esposa como el "Otro" en la Grecia antigua.

El teatro clásico creó así personajes de una gran profundidad y de inmensa trascendencia y pervivencia en la literatura posterior, personajes de un vasto legado interpretativo y mimético que, como podrá concluirse de nuestras referencias, muestran una importante trayectoria en la dramaturgia argentina, en especial a partir de la segunda mitad del s. XX. Tal es el caso de Antígona y Medea, figuras de una incidencia comparativamente mayor en relación a otras de la mitología griega, cuya proyección en el teatro nacional de las últimas décadas pone de relieve asimismo su vigencia como expresión de la alteridad ${ }^{4}$.

Ciertamente el nuevo escenario americano, definido en buena medida por las fronteras geográficas de la conquista "civilizadora", por un borde territorial configurado en el antagonismo de civilización y barbarie, puso al descubierto formas ignoradas de alteridad, como la de ese "Otro" preexistente, el indio, protagonista de varias de las nuevas versiones míticas latinoamericanas (e.g. Antigona Vélez, Medea mapuche). Un rasgo común a las reescrituras de nuestro continente, como se ha reconocido, es la resistencia de los personajes dramáticos a compartir el universo homodiegético de sus predecesores clásicos ${ }^{5}$. En el caso de las Antígonas y Medeas nacionales del último medio siglo, y más allá de una alteridad que se corresponde con las nuevas coordenadas espacio-temporales, es posible destacar la vinculación con aquella otredad que le viene determinada por su género. Concebidas en un escenario patriarcal predominante, nacidas en el contexto histórico de las luchas y conquistas de las mujeres en el terreno político y social de la Argentina de las últimas décadas, estas nuevas Antígonas y Medeas se constituyen desde su propia especificidad cultural asimismo en testimonio de la voz del "Otro".

Ciñéndonos a los límites de este trabajo, y basándonos en buena medida en los datos de investigaciones previas, comenzaremos por puntualizar, los resultados del relevamiento de la presencia de estas dos figuras en nuestro teatro nacional en el período del último medio siglo ${ }^{6}$. Referiremos, luego, a la

\footnotetext{
${ }^{4}$ Que Antígona y Medea se cuentan entre las figuras que más han seducido a los dramaturgos contemporáneos lo prueba no solo su vasto legado mimético, sino el hecho de que son varios los casos en que un mismo autor se atrevió a incursionar en nuevas versiones de ambas figuras. Tal es el caso de J. Anouilh con sus Antígona (1942) y Medea (1946); José Bergamín Medea, la encantadora (1954) y La sangre de Antígona (1955), y en el caso de un autor argentino, D. Cureses con La Frontera (1964) y La cabeza en la jaula (1987).

${ }^{5}$ Cr. Miranda Cancela (2002); Pianacci (2008).

${ }^{6}$ En el siglo XX, especialmente a partir de la década del 50, se producen nuevas versiones teatrales de tragedias griegas. Antígona Vélez de Leopoldo Marechal, Electra (1964) de Julio
} 
Acerca de los imaginarios trágicos de alteridad y su pervivencia en el teatro argentino actual

resemantización de la alteridad en dos obras que representan una de las más nuevas versiones de Antígona y de Medea que ofrece nuestro teatro nacional: Antigonas, linaje de hembras (2001) de Jorge Huertas y Medea de Moquehua (1992) de Luis M. Salvaneschi.

Sobre el mito de Antígona en particular, y su lugar en el teatro latinoamericano de posguerra, contamos con el reciente trabajo de Rómulo E. Pianacci ${ }^{7}$. Una veintena de Antígonas criollas constituyen el corpus de análisis de este estudio, acotado a las piezas producidas entre 1952 y 2007, el momento histórico de un continente "plagado de Creontes" y de un teatro signado, entonces, por una fuerte connotación ideológica, política y social ${ }^{8}$. Entre las Antígonas argentinas se mencionan':

Antígona Vélez (195210) de Leopoldo Marechal, obra en seis cuadros ambientada en el período argentino de la conquista del desierto.

El limite (1958) de Alberto de Zabalía, tragedia en dos actos ambientada en el s. XIX, durante el gobierno de Juan Manuel de Rosas.

Imbert, El Reñidero (1966) de Sergio De Cecco, Medea (1967) de Héctor Schujman, y las restantes versiones que puntualizaremos en este trabajo son algunos de los ejemplos. Para el relevamiento que nos proponemos aquí nos hemos basado en los aportes de investigaciones previas: Pianacci (2008); Bañuls Oller \& Crespo Alcalá (2008); López \& Pociña (2010); Zayas de Lima (2010). Ellas no hacen sino confrontarnos con las dificultades de una investigación de esta índole, basada en fuentes que con frecuencia permanecen inéditas.

${ }^{7}$ Cfr. Pianacci (2008). Además del estudio de Pianacci, deben mencionarse para las Antígonas latinoamericanas la investigación de José Vicente Bañuls y Patricia Crespo de la Universidad de Valencia, que pasan revista a más de doscientas recreaciones del mito de Antígona, entre ellas las Antígonas que Pianacci focaliza en su estudio, y el artículo de los profesores A. López y A. Pociña (2010), que recoge, además, la bibliografía referida a las versiones latinoamericanas del mito.

${ }^{8}$ Cfr. Pianacci (2008: 76). El autor analiza una veintena de Antígonas latinoamericanas: Brasil: Pedreira das almas (1979) de Jorge Andrade; Chile: Antígona, historia de objetos perdidos (2002) de Daniela Cápona Pérez; Colombia: Antígona y Actriz (2004) de Carlos Eduardo Satizábal; Cuba: Antígona (1993) de Joel Saéz; México: La joven Antígona se va a la guerra (1968) de José Fuentes Marel, Los motivos de Antígona (2000) de Ricardo Andrade Jardí y La ley de Creón (2001) de Olga Harmony; Nicaragua: Antígona en el infierno (1958) de Rolando Steiner; Perú: Antígona (1964) de Sarina Helfgott y Antígona (2000) de José Watanabe; Puerto Rico: La pasión según Antigona Pérez (1968) de Luis R. Sánchez; República Dominicana: Antígona-Humor (1968) de Franklin Domínguez y Hernández; Venezuela: La fiesta de los moribundos (1966) de César Rengifo y Antígona (1978) de José Gabriel Núñez. Además, el estudio de Pianacci menciona en la introducción otras seis piezas colombianas y una venezolana estrenadas en el Festival Magdalena Antigona en el encuentro "Mujeres, Arte y Parte en la Paz de Colombia” (Bogotá, 2006). López \& Pociña (2010) citan otra Antígona cubana: Detrás queda el polvo (1968) de José Triana.

${ }^{9}$ Las obras que aquí se mencionan han sido citadas por su año de publicación, en muchos de los casos, como se verá, sustancialmente alejado del año de su estreno teatral.

${ }^{10}$ Recientemente la obra volvió a presentarse en el mismo teatro Cervantes cuya temporada inaugurara en 1951. La dirección estuvo entonces a cargo de Enrique Santos Discépolo, y Nancy Navarro actuó en el papel de Antígona. 
La cabeza en la jaula (198711) de David Cureses, tragedia en tres actos ambientada en la villa de Guaduas (Colombia), a comienzos del s. XIX.

Antígona furiosa (1986) de Griselda Gambaro, Antígona atemporal que cuenta su historia en el tiempo de la Argentina de la última dictadura.

Golpes a mi puerta $\left(1988^{12}\right)$ de Juan Carlos Gené, pieza en tres actos ambientada en un lugar indeterminado de Latinoamérica.

Antígonas, linaje de hembras (2001) de Jorge Huertas, que contextualiza la historia de Antígona en una Buenos Aires contemporánea, en un tiempo impreciso posterior a la crisis económica de 2001.

Antígona... con amor $\left(2003^{13}\right)$ de Hebe Campanella, obra breve enmarcada en la Argentina de los años previos al advenimiento de la dictadura (1973-76). Antígona, ;No! (2003) de Yamila Grande (inédita) ${ }^{14}$.

Sobre Medea y su presencia en el teatro latinoamericano, en cambio, no contamos con un estudio sistemático, aunque debemos mencionar aquí aquellos que recogen, aunque solo sea de modo parcial, su presencia en distintos países de nuestro continente ${ }^{15}$. Específicamente sobre las Medeas argentinas, en un reciente artículo de Perla Zayas de Lima se referencian un número importante de versiones, muchas de ellas obras desconocidas de teatristas locales, que permanecen inéditas o han alcanzado una escasa difusión ${ }^{16}$ :

${ }^{11}$ La obra se estrenó con dirección del propio Cureses en el Teatro El Gorro Escarlata (T.E.G.E) el 12 de julio de 1963, y fue reestrenada posteriormente en el Teatro Candilejas de Rauch con la misma dirección el 26 de octubre de 1985. La edición de la obra es, sin embargo, posterior. Fue el mismo grupo de teatro El Gorro Escarlata el que la editó en 1987, con prefacio del escritor argentino Manuel Mujica Láinez.

${ }^{12}$ La obra fue estrenada en Caracas (Venezuela) el 11 de julio de 1984 por el Grupo Actoral 80 (GA 80), que fue el mismo que la representó, un año después, en el Teatro Municipal General San Martín de Buenos Aires. La primera publicación de Torres Agüero Editor fue corregida en una segunda edición de Ediciones de la Flor (1994), que es la que hemos consultado.

${ }^{13}$ La obra, que mereció una mención en el premio EDENOR, fue estrenada y publicada el mismo año en Teatro breve x 5 (Buenos Aires).

${ }^{14}$ Perla Zayas de Lima (2010: 7) menciona también Antígona la necia (2001) de Valeria Folini, espectáculo unipersonal, adaptación de la tragedia sofóclea.

${ }^{15} \mathrm{E}$. Miranda Cancela hace referencia a ocho versiones dramáticas latinoamericanas de la segunda mitad del s. XX: La selva, de Juan Ríos (Perú, 1950); Malintzin (Medea americana), de Jesús Sotelo Inclán (México, 1957); Medea en el espejo, de José Triana (Cuba, 1960); Além do Rio (Medea), de Agostinho Olavo (Brasil, 1961); Gota d'Agua, de Chico Buarque y Paulo Pontes (Brasil, 1975); Medea de Moquegua, de Luis María Salvaneschi (Argentina, 1992); El castillo interior de Medea Camuñas, de Pedro Santaliz (Puerto Rico, 1984); Medea de Reinaldo Montero (Cuba, 1997). A ellas deben añadirse las versiones argentinas, citadas por Perla Zayas de Lima (2010) y las latinoamericanas que referencia L. Campuzano (2007): Des-Medea, de Denise Stoklos (Brasil, 1994); Medea mapuche, de Juan Radrigán (Chile, 2000); Medea llama por cobrar, de Peky Andino (Ecuador, 2001). Cfr. Miranda Cancela (2002); Campuzano (2007).

${ }^{16} \mathrm{Cfr}$. Zayas de Lima (2010). La reiterada presencia de la figura de Medea en la dramaturgia nacional desde los noventa y su preferencia frente a la de Antígona llevan a la autora a concluir que ella se inspira en un tiempo histórico y social que, como el de Eurípides, se muestra escindido y contradictorio, un tiempo en que vivimos "inmersos en una realidad exenta de ilusiones, en una 
La Frontera (1964) de David Cureses.

Medea (1967) de Héctor Schujman, ambientada en Argentina, en la época actual.

La Navarro (198017) de Alberto Drago, "tragedia latinoamericana" en cinco cuadros, cuya acción se sitúa en Luján en la década del 20.

Ignea Medeas $\left(1985^{18}\right)$ de Juan Jerónimo Brignone (inédita).

Medea, paisaje de hembras (198719), creación colectiva de Máximo Salas, Laura Beltramo y Silvina Fernández Farel (inédita).

Despojos para Medea (1992) de José Luis Valenzuela.

Medea de Moquehua ${ }^{20}$ (1992) de Luis M. Salvaneschi, obra en dos actos cuya acción se ubica en la Buenos Aires contemporánea.

La Hechicera $\left(1997^{21}\right)$ de José Luis Alves, obra en 7 cuadros que sitúa la historia de Medea en el Tucumán del período colonial.

Medea del Paraná (2004) de Suellen Worstell de Dornbrooks (inédita).

Medea Fragmentada (2006) de Clodet y María Barjacoba (inédita).

De entre las Antígonas nacionales, y en relación con el tema que nos ocupa, destaca la versión de Huertas, Antígonas, linaje de hembras, representada por primera vez en Grecia en agosto de 2001 y estrenada finalmente en Argentina en septiembre de $2002^{22}$. La pieza, una versión poética y aporteñada, notoria por su brevedad y por el sincretismo de sus componentes dramáticos, se articula en torno a las escenas sustanciales del drama sofócleo (el encuentro entre Antígona e Ismena, el anuncio de Creonte de la prohibición de sepultura de Polinices, el descubrimiento del guardián de la acción transgresora de Antígona, los enfrentamientos sucesivos de Creonte con Antígona, Hemón y Tiresias, el lamento de despedida de la condenada hija de Edipo). Estas escenas son resignificadas a partir de un nuevo universo diegético (la contextualización de la acción en una Buenos Aires del siglo XXI en la que se entrecruzan de modo

ciudad en la que no hay ley ni justicia, ni orden, que no puede ya albergar Antígonas piadosas y sacrificadas, sino Medeas que dan curso libra a la ira, a la venganza y a la barbarie, conscientes de que todo crimen puede quedar impune" (p. 21).

${ }^{17}$ Texto disponible en http://www.autores.org.ar/adrago/obras.htm.

${ }^{18} \mathrm{La}$ obra fue escrita y dirigida por su autor bajo el pseudónimo de Iánnis Zómbolas.

${ }^{19}$ Versión libre de la tragedia de Eurípides, dirigida por J. Suárez y Q. Canellas, calificada como "teatro de transgresión". Participó de la Bienal de Arte Joven en Ciudad de Buenos Aires (1988) y del Festival de Teatro de Pelotas (1988).

${ }^{20}$ La obra ha sido indistintamente citada como Medea de Moquegua o Medea de Moquehua, en referencia a Moquehuá, nombre del pequeño poblado del partido de Chivilcoy del que proviene Medea. Como Las Marianas, otro poblado igualmente mencionada en la obra de Salvaneschi, se trata de parajes rurales surgidos al amparo del ferrocarril.

${ }^{21}$ La obra fue editada por Emcor en 1997.

${ }^{22}$ La obra se estrenó en 2002 en el Teatro Argentino de La Plata, bajo la codirección de Roberto Aguirre; en noviembre del mismo año se presenta en el Auditórium Jorge Luis Borges de la Biblioteca Nacional de Buenos Aires. 
permanente las referencias al pasado y al futuro del país), y de la incorporación de personajes identitarios: el Río (un Río de La Plata contaminado por los muertos desaparecidos durante la última dictadura militar), el Bandoneón (instrumento emblemático de la música porteña), la Embalsamada Peregrina (personaje que encarna la figura de una mítica Eva Perón, un alter ego de Antígona y un espejo de la ultrajada condición de Polinices) y un nuevo Tiresias (el fantasma de J. L. Borges). La obra mantiene una clara relación intertextual con la tragedia de Sófocles en los 19 breves fragmentos escénicos que la componen, mostrándose a un modo esencialmente fiel y ostensivamente transgresora con respecto a su hipotexto. Acaso uno de los puntos sustanciales de esta fidelidad radica precisamente en el modo en que el protagonismo femenino en la pieza se relaciona con los imaginarios de alteridad.

Ya la pluralidad del nombre "Antígonas" y la extraña mezcla de admiración e insulto que encierra la expresión "linaje de hembras" en el título de la pieza remiten a un conflicto genérico inmanente al mito, que reactualizaba el teatro trágico en su representación del "Otro". Dicho conflicto se reafirma en la versión de Huertas no solo mediante la incorporación de nuevos personajes (tal es el caso del controversial personaje de la Embalsamada Peregrina, que permite repasar el papel de la mujer en la historia sociopolítica argentina del último medio siglo), sino mediante el modo en que el dramaturgo resuelve personajes tradicionales del drama como el personaje colectivo del coro, al que le otorga una función central en su pieza. Se trata en Antigonas de un coro de mujeres, no de ancianos tebanos como en la tragedia sofóclea; ellas alzan su voz frente al abuso masculino, en un mundo en que la lucha femenina se plantea como la lucha de la/s Antígona/s-hembras enfrentadas al poder del "macho"- Creonte. La(s) Antígona(s) de Huertas encarna(n), pues, la raza genérica, esa raza de mujeres que, como la hija de Edipo, se rebelan y claman por sus derechos en una sociedad de hombres en la que son asimiladas recurrentemente a lo marginal:

Coro: Nosotras Antígonas

Las novias de la mugre

del hedor madres.

Las manchadas, las sucias,

las bárbaras.

Yo sé cómo se llama mi herida:

Hembras

Yeguas

Brujas

Locas

Putas.

Siempre Antígonas. 
Las de fatales y porteños padres

hermanas de hermanos

que se vacían de sangre ("Adiós, Antígona”, 62).

De nuestras Medeas, la obra Medea de Moquehua del dramaturgo y poeta Luis María Salvaneschi ${ }^{23}$ recupera también los imaginarios de alteridad en el marco de la contextualización del drama en una Buenos Aires contemporánea. Como la versión de Huertas, la de Salvaneschi tiene una notoria relación con su hipotexto, que se pone de relieve en la fidelidad al orden de secuencias de la tragedia euripidea. ${ }^{24}$ En relación con los personajes, sin embargo, solo la pareja de protagonistas - Medea y Jasón-conservan sus nombres. Creonte es en cambio "el dueño del hotel", un albergue de baja categoría que ha logrado mantener gracias a la colaboración de un Jasón cuyos servicios paga con el matrimonio de su hija. Dos viejos innominados (un jubilado que oficia de sereno y una sirvienta que acompaña a su señora en sus reiterados exilios criminales) asumen con un protagonismo más sostenido el rol de los esclavos anónimos del drama euripideo, trasladados por Salvaneschi a un espacio citadino que domina el poder del dinero.

El nuevo universo diegético de esta Medea desnuda con crudeza la imagen del exilio y marginalidad de la protagonista. Medea, oriunda de Moquehuá (un pequeño e ignoto pueblo de provincia), ha cambiado en la versión de Salvaneschi sus dotes de hechicera por las cartas del Tarot, pero en las "paredes de cartón, vergüenza y suspiros" de la ciudad en que ahora habita, allí "donde nada es privado” (p. 11), la inunda idéntica añoranza por su hogar natal como a su homónima euripidea. La otredad de esta Medea, más que nacer de su condición de mujer/esposa (una mujer unida a su hombre sin "papel legal", p. 23), descubre aspectos de la historia social de nuestro país. Otredad hiperbólica, como en la tragedia, que nace aquí de lo femenino en el cruce con una "triple marginación, la que sufre un pueblo de provincia respecto de la capital, la de las clases bajas respecto de las pudientes, y la dependencia de un país periférico en su relación con una cultura central" (Zayas de Lima, 2010: 16).

Las versiones que reseñamos de Antígona y Medea comparten entre otros rasgos las discordancias estilísticas que surgen de la imbricación en el texto de variados registros lingüísticos y musicales, lo que contribuye a remarcar

${ }^{23}$ Luis María Salvaneschi, nacido en Olivos (provincia de Buenos Aires), estrenó varias obras teatrales de su propia autoría o coautoría ("Vida y Risas del siglo XV", 1960; "Un, Dos, Tres", 1963; "El agua de todos los ríos", 1980; “Tiempo de fantasía”, 1982; "Segunda Familia”, 1984; "Una historia en cortocircuito", 1989), entre las cuales no se cuenta, por cierto, la pieza que es objeto de nuestro análisis, editada -aunque no estrenada- en el año 1992, en una edición por cierto limitada, que dificulta notoriamente el acceso al texto.

${ }^{24}$ Notable es, por ejemplo, la reelaboración de la escena prologal. 
asimismo la otredad de las protagonistas. Destacamos también el rol que en tal sentido desempeña el coro. ${ }^{25}$ Aunque se trata de dos coros de características notoriamente diferentes (un coro de mujeres no individualizados, en el caso de la Antígonas de Huertas, y un coro de murgueros individualizados, en la Medea de Salvaneschi), ambas versiones incorporan esta voz colectiva como expresión de lo marginal ${ }^{26}$.

Las limitaciones de nuestra investigación nos impiden aquí aventurar conclusiones como la que llevan a Perla Zayas de Lima (2010) a afirmar, en torno a la presencia de estas figuras míticas femeninas en la dramaturgia nacional, que el nuestro es más bien un tiempo de Medeas bárbaras y vengativas, no de Antígonas piadosas y sacrificadas. Demostrada la vigencia sostenida de ambas figuras, creemos que las referencias y los ejemplos escogidos permiten al menos plantear dos cuestiones importantes que señalaremos a modo de cierre: 1) Algunas figuras míticas han cobrado renovado interés y despertado nuevas lecturas en el teatro nacional de la última parte del siglo XX, "a partir del descubrimiento del otro en medio del complejo acontecer contemporáneo" (Miranda Cancela, 2002: 71); 2) el modo en que el referente clásico sigue aportando su carga simbólica, y la forma en que explica o se explica en nuestra historia sigue siendo hoy una deuda pendiente para un teatro en gran medida desconocido. El relevamiento exhaustivo de las obras contemporáneas que de forma explícita se basan n mitos clásicos aún resta por hacerse. Lo expuesto pretende ser una primera contribución.

${ }^{25}$ En un reciente ensayo, H. Foley (2007) concluía que las adaptaciones y representaciones más contemporáneas de la tragedia testimonian la revalorización de la voz colectiva del coro, más allá de las complejidades que plantea su inclusión en una obra.

${ }^{26}$ Jorge Huertas opta por un coro unívocamente femenino, Luis M. Salvaneschi, en cambio, por un coro de voces mixtas identificadas: el señor y la señora del bombo, el director de la murga, un travesti, la reina de la murga y el Tony. Estas voces se caracterizan por una desacralización ostensiva del lenguaje, manifiesta en el uso de registros lunfardos (en el caso de Huertas), y en ocasiones acompañado de gestos procaces (en el caso de Salvaneschi). 


\section{Bibliografía}

Alonso, L. (2010), “¿Qué será se la reina del Plata?’: Hybris, castigo y enigma en Antigonas: linaje de hembras de J. Huertas", en G. Fabry, I. Logie \& P. Decock (eds.), Los imaginarios apocalipticos en la literatura hispanoamericana contemporánea, Bern, pp. 313-326.

Bañuls Oller,J. V. - Crespo Alcalá, P. (2006), “Antígona, la génesis de un mito”, en J. V. Bañuls Oller, F. De Martino \& C. Morenilla Talens (eds.), El teatro clásico en el marco de la cultura griega y su pervivencia en la cultura occidental. El teatro greco-latino y su recepción en la tradición occidental, Bari, 15-58.

(2008), Antígona(s) mito y personaje. Un recorrido desde los orígenes, Bari.

Campuzano, L. (2007), "Medea en el metro de Nueva York", en J. V. Bañuls Oller - F. De Martino \& C. Morenilla Talens (eds.), El teatro grecolatino y su recepción en la tradición occidental. 2, Bari.

Cartledge, P. (1993), The Greeks. A Portrait of Self and Others, Oxford (rev. edn. 2002).

Escobar Villegas, J. C. (2000) Lo imaginario. Entre las ciencias sociales y la bistoria, Medellín.

Foley, H. (2001), Female Acts in Greek Tragedy, Princeton.

(2007), "Envisioning the Tragic Chorus on the Modern Stage", en C. Kraus, S. Goldhill, H. Foley \& J. Elsner (eds.) Visualizing the Tragic. Drama, Myth and Ritual in Greek Art and Literature, Oxford, pp. 353378.

López, A. - Pociña, A. eds. (2001), Medeas. Versiones de un mito desde Grecia hasta hoy, 2 vols., Granada.

(2009), En recuerdo de Beatriz Rabaza. Comedias, Tragedias y Leyendas Grecorromanas en el Teatro del s. XX, Granada.

- (2010), "La eterna pervivencia de Antígona”, FlorIlib 21, 345-370.

Martindale, Ch. (2007), "Reception”, en C. W. Kallendorf (ed.), A Companion to the Classical Tradition, Singapore; pp. 297-312.

Miranda Cancela, E. (2002), "Medea: otredad y subversión en el teatro latinoamericano contemporáneo", en C. Morenilla Talens \& F. De Martino (eds.), El Perfil de les ombres: el teatre clàssic al marc de la cultura grega i la seua pervivencia dins la cultura occidental, Bari; pp. 317-321.

Pianacci, R. E. (2008), Antígona: una tragedia latinoamericana, Irvine, CA.

Vernant, J-P. - Vidal-Naquet, P. (1972), Mito y tragedia en la Grecia antigua I, Madrid. 
Lidia Gambon

Zayas de Lima, P. (2010), "Mitos griegos en el discurso teatral argentino", Telondefondo 11, <http//:www.telondefondo.org >. 